\title{
Investigating the Impact of Virtual Reality and Gamification on Improving Physical Activities in School
}

Reza Roshanpour ( $\nabla$ r.roshanpour70@gmail.com )

Iran University of Science and Technology https://orcid.org/0000-0002-1993-7122

Mohammad Hazegh Nikroo

Shaheed Beheshti University of Medical Sciences

\section{Research}

Keywords: gamification, virtual reality, physical activity, motivation

Posted Date: July 29th, 2020

DOI: https://doi.org/10.21203/rs.3.rs-47976/v1

License: (c) (1) This work is licensed under a Creative Commons Attribution 4.0 International License.

Read Full License 


\section{Abstract}

Background: The rise of obesity creates a critical health problem in childhood which can establish obesity in adulthood. It is significant in the first years of life to participate in physical activity program. In other words, children have to perform physical activity for preventing obesity and toward reducing obesity in adulthood. In this regard, it seems to be important in elementary schools. In this regard, interventions were used to perform physical activity. We have utilized virtual reality and gamification as an intervention to increase motivation for exerting physical activity in elementary school. In reality, three critical areas have been identified to enhance quality physical education program include Promoting intrinsic motivation, enhancing perceived physical competence, and creating a mastery-oriented physical-activity environment.

Methods: Mixed quantitative and qualitative study to specify the effects of integration gamification and virtual reality in the physical activity program was used. Analyses were conducted using IBM Statistics SPSS 25.0 software. Also, we used independent-samples T-test to compare results.

Results: Total of 25 elementary students participated in our study. This study performed about combination of gamification and virtual reality games. we divided all the students into diverse groups. Results indicated the use of virtual reality and gamification could enhance motivation in children to perform physical activity in school.

Conclusion: Virtual reality technology and gamification on physical activity environments had a positive effect on the motivation of elementary students. virtual reality and gamification on motivation leads students to achieve higher levels of engagement in performing physical activity.

\section{Introduction}

Today, a sedentary lifestyle is recognized as one of the significant risks for chronic diseases. The importance of mobility and physical activity are increased among health professionals. Currently, inactive and inadequate physical activity is known as a significant concern to WHO, and fourth leading cause of death in the world (Organization, 2019) and the rise of obesity in childhood creates a critical health problem. Inactive can establish obesity in adulthood and physical activity can be prevented the obesity(Geneen et al., 2017; Whitaker, Wright, Pepe, Seidel, \& Dietz, 1997) and a physically active lifestyle plays a vital role in maintaining both physical and mental health. A recent report showed that less than half of preschoolers obtained the recommended $\geq 3$ hours/days of total PA (light, moderate, and vigorous), with at least 1 of these hours in MVPA, recommended by leading international organizations (Health \& Services, 2008; Pate et al., 2015). Also, some studies presented that Latino and African American youth are at odds of meeting daily PA recommendations and higher odds of being overweight/obese (Anderson, Economos, \& Must, 2008; Fakhouri, Hughes, Brody, Kit, \& Ogden, 2013; Piercy et al., 2018). Also, Numerous studies were showed which the prevalence of inactivity, the decrease in physical activity, and the prevalence of obesity' children in Iran (Mohammadpour-Ahranjani, 2011; 
Taymoori, Falhahi, \& Esmailnasab, 2011). However, physical activity for preschool children is vital and the use of an intervention for performing physical activity is significant. (Wilkie, Standage, Gillison, Cumming, \& Katzmarzyk, 2018) were indicated which factors pertaining to the individual, home and school environment played a vital role in performing physical activity. In other research, parental monitoring as a positive determinant to change physical activity behavior and role of neighborhood economic context on physical activity was searched by (Hesketh et al., 2017; Kim \& Cubbin, 2017).

Although, all studies of above-mentioned have shown positive consequences of physical activity in children, but they have not used approaches which increase motivation levels for exerting physical activity. In reality, such as physics, mathematics, chemistry, and other elementary school curricula, physical activity is part of education in schools. The purpose of this study is to use the virtual reality and gamification approach to affect motivation to exert physical activity in children.

The present study intends to answer the following research question.

RQ: Can combination of virtual reality and gamification change student behavior and attract them for performing physical activity?

\section{Literature review}

In all studies have utilized an intervention to perform physical activity successfully. Flexible ecological intervention that educates trainers to offer opportunities for children, enhance MVPA and physical activity energy expenditure in school was used (Pate et al., 2016). Also, this fact which family support is one of the essential elements for influencing physical activity was determined by (Tamimi \& Noroozi, 2016). Furthermore, classroom-based brain breaks as an easy method to support physical activity in students was researched and results indicate which this way can be efficient (Armstrong \& Jenny, 2018). In another research, a hierarchical regression analysis was used to examine PA opportunities for children and showed the importance of teacher existence in a physical activity (Glowacki, Centeio, Van Dongen, Carson, \& Castelli, 2016). Also, the ability of PA increasing in rural schools by environmental and policy interventions by school administers and educators was indicated by (Economo et al., 2018). Also, teaching by using CDs can be useful in decreasing BMI in overweight and obese children and adolescents as-much-as face to face education and participation in physical (Ghatrehsamani et al., 2010). Also, in children with cancer physical activity was examined and results indicated that active video games could play a useful role in increasing physical activity in children (Kauhanen et al., 2014) and physical activity can be useful in cancer treatment. In addition, vast range of environmental intervention has been implemented to improve PA levels. By installing outdoor exercise equipment, reconstructing playground and increasing the amount of open green pace (Cohen, Marsh, Williamson, Golinelli, \& McKenzie, 2012) and a growing number of built environment infrastructural changes (BEICs) to promote active transportation (AT) by walking and bicycling for transportation was examined by (Evenson, Herring, \& Huston, 2005). 
In all studies of above-mentioned interventions was utilized to affect children for changing their behavior to perform physical activity. In this study is aimed to enhance motivation in children to engage themselves. Therefore, we are going to use the virtual reality and gamification to affect them.

In the next section, motivation is defined and is examined in school curricula. Then, the gamification approach will be addressed.

\section{Motivation}

Motivation was interpreted as which describes the direction and extent behavior(Keller, 2009). In other words, motivation is the extent continual effort directed towards a goal (Adams-Wiggins, 2017; Hamzah, Ali, Saman, Yusoff, \& Yacob, 2014). In this regard, if students was derived to learn, they enhance their engagement and increased attempt for task completion than other neutral students in school (Efklides, Kuhl, \& Sorrentino, 2001; Schmidt, 2007). integration of technology into education showed that motivation has increased in some researches (Aşıksoy \& Özdamlı, 2016; Di Serio, lbáñez, \& Kloos, 2013). One of motivational models is ARCS model. The ARCS model was defined as combination motivational concepts, namely attention, relevance, confidence, satisfaction (Keller, 2000) which the aim of ARCS model to increase motivation in learning was determined.

So far, different ARCS model was extracted, ARCS+AT was defined by (Nakajima, Nakano, Ohmori, \& Suzuki, 2011) utilizing stuff and checklist to promote assistant university faculty in e-learning. ARCS-V model which added volition for motivating learner and Volition as actions and attitudes regarding a steady effort to reach a goal was defined by (Keller, 2008a). MVP model as integrative of intention, action control, information processing to explain the performance level of the learner was discussed by (Keller, 2008b). Last model called $A R C S+G$ model which utilized game dynamics to motivate leaner for performing tasks in students. There were various studies which used the ARCS model in education. Impacts of the flipped classroom method adapted to the ARCS' Keller in a physics course was examined and results represented that student were motivated more than the control group (Aşıksoy \& Özdaml,, 2016). In addition, the effect of podcasting on student motivation align with the ARCS model was investigated in the online environment by (Bolliger, Supanakorn, \& Boggs, 2010) and Results indicated that components such as confident, satisfaction, relevance, and attention increased. Also, ARCS' motivation for analysis of the student stimuli in the design of an acid and bases unit in the chemistry was used and results indicated this model can be efficient to enhance motivation in student (Feng \& Tuan, 2005). Another research by (Li \& Keller, 2018) were showed that the ARCS model can apply to a variation of education setting such as course email, specific software, game.

In this paper, we used the $A R C S+G$ model for driving students. In the next section, we address gamification for engaging individuals and virtual reality in different context.

\section{Gamification}


There are very definitions for gamification, but the most applicable is the use of game elements in a nongame context in order to increase engagement (Deterding, Dixon, Khaled, \& Nacke, 2011). The purpose of gamification to change behavior users, and turning undesirable behavior into desirable behavior was defined. Behavior changes by using Elements of gamification include dynamics, mechanics, and aesthetics are performed. We use game mechanics such as point, leaderboard, badge, group tasks, level and dynamic games like reward, status, competition which was determined by (Chan, Nah, Liu, \& Lu, 2018; Khaleel, Sahari, Wook, \& Ismail, 2016) to increase learning motivation. First, we define some mechanics such as point, badge, and leaderboard.

Point: this mechanic is used to reward users through multiple dimensions and different categories (Gafni, Achituv, Eidelman, \& Chatsky, 2018).

Badge: this mechanic is used to promote external recognition that the user comes to new levels and succeeded in the challenges (Gafni et al., 2018). In other words, this type of rewards drive students and their fancy to complete the challenges (da Rocha Seixas, Gomes, \& de Melo Filho, 2016). In this study, we used the trademark of Saaland health club as the badge (figure1).

Leaderboard: this component indicates users' relative position compared to others to indicate students' achievements in order to improve incentives and uses competition as an incentive for behavior of individual (Cagiltay, Ozcelik, \& Ozcelik, 2015; da Rocha Seixas et al., 2016). In our research, we used picture and name of users to challenge and the avatar of games brought for attraction(figure2).

\section{Virtual reality}

Sherman and Craig described virtual reality as the make-up of simulation computers to interact with the environment for the participant through virtual space (Sherman \& Craig, 2002). Using VR can be helpful and enhanced motivation in learning (Freina \& Ott, 2015). It has begun suitable and reliable media to use in elementary school (Roussou, 2004). Thus, VR can be utilized as a simulation-based education and permits students and educators to practice skillfulness for improvement, repetition, and non-dangerous failure (Jensen \& Konradsen, 2018). In this regard, the use of virtual reality in different context was investigated. Gamification and virtual reality in teaching 3D arts for examining the engagement of university students was utilized by (Villagrasa, Fonseca, \& Durán, 2014) and results showed integration virtual reality and gamification can increase motivation in individual. Also, in other research, the use of AR for training, 3D presentations and interaction techniques for a better perception of scientific and cultural content is useful to engage student in learning (Bogen, Wind, \& Giuliano, 2006). Another research a virtual physics laboratory in physics class was discussed by (Loftin, Engleberg, \& Benedetti, 1993) and results reveal motivation improved for researching.

\section{Methodology}

we used a mixed quantitative and qualitative study to specify the effects of integration gamification and virtual reality in the physical activity program. We utilized several games such as "power beat, beat saber, 
ninja fruit, super saver, big brother, table tennis, traffic rider, piano tiles, and finally box VR". Each group must play games with physical activity and after exerting physical activity and playing game successfully, they receive a badge. Analyses were conducted using IBM Statistics SPSS 25.0 software. Also, we used independent-samples T-test to compare results. The Independent Samples T-Test compares the means of two independent groups in order to determine whether there is statistical evidence that the population means are significantly different. In the next sections, we defined participants, procedure, and measure.

\section{Participants}

Total of 25 elementary students participated in our study. We performed this at the "Saaland Health club". Saaland Health club is a profit and research institute in Iran whose goal is education and promotion of health to students with 5-15 old. Saaland Health club uses appealing games and virtual reality to affect children. Also, it advises parents to help their students for performing physical activity in home. We used traditional and experimental ways. In the traditional method, children are asked to exert physical activity such as running, jumping, and other physical activities are educated by teachers, but in the experimental way the virtual reality in the same cases of physical activities is used and exerted by gamification approach.

\section{Procedure}

This study was carried out over a four- week period. Each student participated in process including two times a week for 45 minutes at the Saaland health club. Due to restrictions imposed by education institution, it was not possible to break up students into two groups: an experimental group and a control group. Consequently, all the students participated in both learning scenarios. To perform this study about combination gamification and virtual reality games, we divided all the students into diverse groups. We apply point, leaderboard, badge, group tasks, level to charm games. First, the story of the game was told to them and children were informed the game. Each group must go through three levels which contain three stages, and at every stage is assigned a point as a record. Every player(student) who earns score, a special badge attaches on their profile. The requirement to go to the higher level receiving three badges was determined. If all members of the group receive all badges of the stage, a celebration for finishing the stage will be held for them and go to the higher stage. Also, we permit students freely choose the games of each stage.

Levels are defined as follows: (Table 1)

Level 1: consist of three games; ninja fruit, super saver, and traffic rider. The first game in the form of virtual reality games and the second game in the form of Kinect games, and the third game is an innovative game in which the students are sitting on a stationary bike and by pedaling the virtual motorcycle starts to move in the monitor. 
Level 2: contain three games, namely power beat, big brother, piano tiles. Again, the first game is virtual reality, the second game is Kinect games, and the third game is an innovative game that children are placed in an artificial boxing ring and have to play the piano with the boxing glove.

Level 3: comprise three games called, beat saber and box VR that both are virtual reality and the third game is raly taly in the form Kinect game.

for each group was used a profile to see their level that they have gained. Also, in order to enhance attention to improve the physical activity in all the students, we create situations that sound of the games played in the environment(figure3,4).

\section{Measure}

physical activity enjoyment scale was used (PACES) in this search (Moore et al., 2009) (Table 2) and for measuring enjoyment apply questionnaires among children. Children are young, thus it is difficult for them to understand the Likert spectrum, Thus" yes", and "no" answers were used to answer questions. We show each question with abbreviation "Q".

\section{Results}

Twenty-five students participate in our approach ( $M$ age: 8, 15 males, 10 females) from two schools. After performing traditional physical activity, the questionnaire gives them and afterward exerting our design, children was wanted to reply to questions. We divided males into three groups of five members, and females were two groups; each of groups include five members. We used "prob" to compare methods which $p<0.05$ indicated significant difference in traditional and experimental design. (Table 3) (Table 4)

Results from two tables exhibited significant difference in traditional and experimental methods. In other words, "Prob" in Questions about satisfaction and pleasure indicate significant difference in methods. Also, students were motivated to perform physical activity due to challenges and satisfaction. Also, after doing our experiment, we understood that children liked to exert physical activity in their school. But in related to females (Table 3 ) the second question $(p=0.074)$ indicates no significant difference, because females are weaker than males. We looked at results and found that females like physical activity through virtual reality and the gamification approach.

\section{Discussion}

In reality, such as physics, mathematics, chemistry, and other elementary school curricula, physical activity is one of the learning plans in school. Thus, it is important to exert Physical activity and in providing an active environment in elementary students. In other words, an active environment is needed to motivate students to initiate and exert physical activity. Three critical areas that have been identified to enhance quality physical education program including Promoting intrinsic motivation, enhancing perceived physical competence, and creating a mastery-oriented physical-activity environment. Also, two 
promising social cognitive variables which have been related to youth physical activity are MasteryOriented environment and attraction(Alderman et al., 2006; Brustad, 1993). In this research, for reaching these three concepts used Their strategies. In this research the concept of "promoting intrinsic motivation" to engage in an activity for satisfaction was examined and confirmed the research by (Alderman, Beighle, \& Pangrazi, 2006) . Also, the desire to attempt new experience and continue to participate in physical activity often desponds on a youngster's perception of her or his ability level, or perceived competence (Alderman et al., 2006) which this perception creates confidence and this concept was confirmed in this research.

In our design, we tried to use three components through their strategies (Alderman et al., 2006) and changing environment to affect students. In this regard, the purpose of this study is to compare physical activity in traditional and our experimental which based on ARCS $+G$ model that including satisfaction, Confidence, relevance, and attention which can be used to enhance motivation in a quality physical education program.

The participants were selected into different groups. Each group used a gamified platform and virtual reality which gamification elements such as levels, profile, rewards in the form of badges and points and the same group used a non-gamified platform. In other words, we used mechanics such as; point, leaderboard, badge, group tasks, level to reach satisfaction, confidence, and Mastery-Oriented. Also, we create situations that sound of the games played in the environment to increase attention. Results indicate that Promoting intrinsic motivation produces satisfaction, enhancing perceived physical competence produces confident, and mastery-oriented physical-activity environment establishes relevance. Furthermore, we found that by adding another factor called "attention", students performed better physical activity. We utilized males and females to examine this design and Participations in both sexes confirmed that this design influenced their motivation.

Also, Students embrace physical activity with very pleasure and their enthusiasm was enhanced to exert physical activity. Also, we found females are weaker than males as well as we saw males had vibrancy and they liked to look at student's faces and prefer the crowd to the person. In other words, they liked to be in the crowd to perform physical activity and they were not afraid of failure and expressed fear of failure later.

In contrast, females tired quickly and lose their spirits with failure. We found females were more careful to exert physical activity than males. Also, females listen to their teammates' conversations more carefully than males.

Feasibility of using virtual reality in elementary school education;

From the usability study, it can be concluded that students performed physical activity with no difficulty how to use the virtual reality learning system. They successfully and timely completed the tasks assigned. Technical problems found were not serious enough to diminish the enthusiasm of students to accomplish the learning activities supported by virtual reality technology. 
Benefits of using gamification approach in learning;

During the sessions, students showed high levels of engagement and the gamification learning environment was repeatedly described as appealing. Students expressed their satisfaction in terms of material used, the possibility Providing a choice of several games is also likely to be more developmentally appropriate. Several students reported they achieved high levels of attention to physical activity while performing tasks. They also claimed that had managed to exert physical activity in their home. Indeed, At the end of each exercise session, students spontaneously formed discussion groups where each one described and analyzed in detail parts of the material, they found particularly interesting and motivated each other to go to the higher level faster.

\section{Conclusion}

The quantitative results of this research study showed that the use of virtual reality technology and gamification on physical activity environments had a positive effect on the motivation of elementary students. The effect has been analyzed in comparison with traditional and experimental course. Results from this study exhibited significant difference in traditional and experimental methods. A clear improvement on motivational factors including relevance, confidence, attention and the satisfaction for the learning environment based on virtual reality and gamification compared with a traditional learning environment was noticed. These results indicated virtual reality and gamification could affect performing physical activity, and environment was more appealing and easier to exert in school. The use of an intervention to attract children to exert physical activity for preventing obesity is significant. In reality, as a result of our study, we conclude that the positive impact of virtual reality and gamification on motivation leads students to achieve higher levels of engagement in performing physical activity. Further research is necessary to determine the effectiveness of our design on physical acivity in high schools.

\section{Declarations}

\section{Acknowledge}

We are deeply grateful to students that gently collaborated on this research study. We would also like to thank Professor Mohammad Fathian from the school of Industrial Engineering at Iran University of Science and Technology for his guidance.

\section{Ethics approval and consent to participate}

Approval to conduct the study was gained from Iran University Science and Technology.

\section{Consent for publication}

All participants provided written informed consent before participating in the study, which included consent to publish anonymous quotes from individual participants. 
Availability of supporting data

If data is request by researchers, they will available.

\section{Competing interests}

The authors declare that they have no competing interests.

\section{Funding}

No funding has been received for this research.

\section{Authors' contributions}

Reza Roshanpour designed the study and carried out the statistical analysis. Mohammad Hazegh Nikroo drafted andrevised the manuscript. All authors read and approved the final manuscript.

\section{References}

1. Adams-Wiggins, K. (2017). Enhancing Student Motivation.

2. Alderman, B. L., Beighle, A., \& Pangrazi, R. P. (2006). Enhancing motivation in physical education. Journal of Physical Education, Recreation \& Dance, 77(2), 41-51.

3. Anderson, S. E., Economos, C. D., \& Must, A. (2008). Active play and screen time in US children aged 4 to 11 years in relation to sociodemographic and weight status characteristics: a nationally representative cross-sectional analysis. BMC Public health, 8(1), 366.

4. Armstrong, T., \& Jenny, S. E. (2018). Increasing Physical Activity in Schools 30 Seconds at a Time. Strategies, 31(1), 51-56.

5. Aşıksoy, G., \& Özdamlı, F. (2016). Flipped Classroom adapted to the ARCS Model of Motivation and applied to a Physics Course. Eurasia Journal of Mathematics, Science \& Technology Education, 12(6).

6. Bogen, M., Wind, J., \& Giuliano, A. (2006). ARISE-Augmented Reality in school environments. Paper presented at the European Conference on Technology Enhanced Learning.

7. Bolliger, D. U., Supanakorn, S., \& Boggs, C. (2010). Impact of podcasting on student motivation in the online learning environment. Computers \& Education, 55(2), 714-722.

8. Brustad, R. J. (1993). Who will go out and play? Parental and psychological influences on children's attraction to physical activity. Pediatric exercise science, 5(3), 210-223.

9. Cagiltay, N. E., Ozcelik, E., \& Ozcelik, N. S. (2015). The effect of competition on learning in games. Computers \& Education, 87, 35-41.

10. Chan, E., Nah, F. F.-H., Liu, Q., \& Lu, Z. (2018). Effect of gamification on intrinsic motivation. Paper presented at the International Conference on $\mathrm{HCl}$ in Business, Government, and Organizations. 
11. Cohen, D. A., Marsh, T., Williamson, S., Golinelli, D., \& McKenzie, T. L. (2012). Impact and costeffectiveness of family fitness zones: a natural experiment in urban public parks. Health \& place, 18(1), 39-45.

12. da Rocha Seixas, L., Gomes, A. S., \& de Melo Filho, I. J. (2016). Effectiveness of gamification in the engagement of students. Computers in Human Behavior, 58, 48-63.

13. Deterding, S., Dixon, D., Khaled, R., \& Nacke, L. (2011). From game design elements to gamefulness: defining" gamification". Paper presented at the Proceedings of the 15th international academic MindTrek conference: Envisioning future media environments.

14. Di Serio, Á., Ibáñez, M. B., \& Kloos, C. D. (2013). Impact of an augmented reality system on students' motivation for a visual art course. Computers \& Education, 68, 586-596.

15. Efklides, A., Kuhl, J., \& Sorrentino, R. M. (2001). Trends and prospects in motivation research: Springer.

16. Evenson, K. R., Herring, A. H., \& Huston, S. L. (2005). Evaluating change in physical activity with the building of a multi-use trail. American journal of preventive medicine, 28(2), 177-185.

17. Fakhouri, T. H., Hughes, J. P., Brody, D. J., Kit, B. K., \& Ogden, C. L. (2013). Physical activity and screentime viewing among elementary school-aged children in the United States from 2009 to 2010. JAMA pediatrics, 167(3), 223-229.

18. Feng, S.-L., \& Tuan, H.-L. (2005). Using ARCS model to promote 11th graders' motivation and achievement in learning about acids and bases. International journal of science and mathematics education, 3(3), 463-484.

19. Freina, L., \& Ott, M. (2015). A literature review on immersive virtual reality in education: state of the art and perspectives. Paper presented at the The International Scientific Conference eLearning and Software for Education.

20. Gafni, R., Achituv, D. B., Eidelman, S., \& Chatsky, T. (2018). The effects of gamification elements in elearning platforms. Online Journal of Applied Knowledge Management (OJAKM), 6(2), 37-53.

21. Geneen, L. J., Moore, R. A., Clarke, C., Martin, D., Colvin, L. A., \& Smith, B. H. (2017). Physical activity and exercise for chronic pain in adults: an overview of Cochrane Reviews. Cochrane Database of Systematic Reviews(4).

22. Ghatrehsamani, S., Khavarian, N., Beizaei, M., Ramedan, R., Poursafa, P., \& Kelishadi, R. (2010). Effect of different physical activity training methods on overweight adolescents. ARYA atherosclerosis, 6(2), 45.

23. Glowacki, E. M., Centeio, E. E., Van Dongen, D. J., Carson, R. L., \& Castelli, D. M. (2016). Health promotion efforts as predictors of physical activity in schools: An application of the diffusion of innovations model. Journal of School Health, 86(6), 399-406.

24. Hamzah, W. A. F. W., Ali, N. H., Saman, M. Y. M., Yusoff, M. H., \& Yacob, A. (2014). Enhancement of the ARCS model for gamification of learning. Paper presented at the 2014 3rd International Conference on User Science and Engineering (i-USEr). 
25. Health, U. D. o., \& Services, H. (2008). Physical activity guidelines advisory committee report, 2008. In: Washington, DC.

26. Hesketh, K. R., O'Malley, C., Paes, V. M., Moore, H., Summerbell, C., Ong, K. K., . . van Sluijs, E. M. (2017). Determinants of change in physical activity in children $0-6$ years of age: a systematic review of quantitative literature. Sports medicine, 47(7), 1349-1374.

27. Jensen, L., \& Konradsen, F. (2018). A review of the use of virtual reality head-mounted displays in education and training. Education and Information Technologies, 23(4), 1515-1529.

28. Kauhanen, L., Järvelä, L., Lähteenmäki, P. M., Arola, M., Heinonen, O. J., Axelin, A., . . Salanterä, S. (2014). Active video games to promote physical activity in children with cancer: a randomized clinical trial with follow-up. BMC pediatrics, 14(1), 94.

29. Keller, J. M. (2000). How to integrate learner motivation planning into lesson planning: The ARCS model approach. VII Semanario, Santiago, Cuba, 1-13.

30. Keller, J. M. (2008a). First principles of motivation to learn and e-learning. Distance Education, 29(2), 337-338.

31. Keller, J. M. (2008b). An integrative theory of motivation, volition, and performance. Technology, Instruction, Cognition, and Learning, 6(2), 79-104.

32. Keller, J. M. (2009). Motivational design for learning and performance: The ARCS model approach: Springer Science \& Business Media.

33. Khaleel, F. L., Sahari, N., Wook, T. S. M. T., \& Ismail, A. (2016). Gamification elements for learning applications. International Journal on Advanced Science, Engineering and Information Technology, 6(6), 868-874.

34. Kim, Y., \& Cubbin, C. (2017). The role of neighborhood economic context on physical activity among children: Evidence from the Geographic Research on Wellbeing (GROW) study. Preventive medicine, $101,149-155$.

35. Lau, K. W., \& Lee, P. Y. (2015). The use of virtual reality for creating unusual environmental stimulation to motivate students to explore creative ideas. Interactive Learning Environments, 23(1), 3-18.

36. Li, K., \& Keller, J. M. (2018). Use of the ARCS model in education: A literature review. Computers \& Education, 122, 54-62.

37. Loftin, R. B., Engleberg, M., \& Benedetti, R. (1993). Applying virtual reality in education: A prototypical virtual physics laboratory. Paper presented at the Proceedings of 1993 IEEE Research Properties in Virtual Reality Symposium.

38. Mohammadpour-Ahranjani, B. (2011). The epidemiology and prevention of childhood obesity in Tehran, Iran. University of Birmingham,

39. Moore, J. B., Yin, Z., Hanes, J., Duda, J., Gutin, B., \& Barbeau, P. (2009). Measuring enjoyment of physical activity in children: validation of the Physical Activity Enjoyment Scale. Journal of applied sport psychology, 21(S1), S116-S129. 
40. Nakajima, K., Nakano, H., Ohmori, F., \& Suzuki, K. (2011). The Effectiveness of campus-wide elearning supports designed by an extended ARCS model. International Journal for Educational Media and Technology, 5(1), 150-161.

41. Organization, W. H. (2019). Global action plan on physical activity 2018-2030: more active people for a healthier world: World Health Organization.

42. Pate, R. R., Brown, W. H., Pfeiffer, K. A., Howie, E. K., Saunders, R. P., Addy, C. L., \& Dowda, M. (2016). An intervention to increase physical activity in children: a randomized controlled trial with 4-year-olds in preschools. American journal of preventive medicine, 51(1), 12-22.

43. Pate, R. R., O'Neill, J. R., Brown, W. H., Pfeiffer, K. A., Dowda, M., \& Addy, C. L. (2015). Prevalence of compliance with a new physical activity guideline for preschool-age children. Childhood obesity, 11(4), 415-420.

44. Piercy, K. L., Troiano, R. P., Ballard, R. M., Carlson, S. A., Fulton, J. E., Galuska, D. A., . . Olson, R. D. (2018). The physical activity guidelines for Americans. Jama, 320(19), 2020-2028.

45. Rogers, L. Q., Carter, S. J., Williams, G., \& Courneya, K. S. (2018). Physical activity. In Handbook of Cancer Survivorship (pp. 287-307): Springer.

46. Roussou, M. (2004). Learning by doing and learning through play: an exploration of interactivity in virtual environments for children. Computers in Entertainment (CIE), 2(1), 10-10.

47. Schmidt, J. T. (2007). Preparing students for success in blended learning environments: Future oriented motivation and self-regulation. Imu,

48. Sherman, W. R., \& Craig, A. B. (2002). Understanding virtual reality: Interface, application, and design: Elsevier.

49. Tamimi, H., \& Noroozi, A. (2016). Determinants of physical activity in high school girl students: Study Based on Health Promotion Model (HPM). Journal of health, 6(5), 527-537.

50. Taymoori, P., Falhahi, A., \& Esmailnasab, N. (2011). Application of the Health Promotion Model in studying physical activity behavior of students in Sanandaj, Iran. Journal of school of public health and institute of public health research, 9(1), 35-46.

51. Villagrasa, S., Fonseca, D., \& Durán, J. (2014). Teaching case: applying gamification techniques and virtual reality for learning building engineering $3 D$ arts. Paper presented at the Proceedings of the second international conference on technological ecosystems for enhancing multiculturality.

52. Whitaker, R. C., Wright, J. A., Pepe, M. S., Seidel, K. D., \& Dietz, W. H. (1997). Predicting obesity in young adulthood from childhood and parental obesity. New England journal of medicine, 337(13), 869-873.

53. Wilkie, H. J., Standage, M., Gillison, F. B., Cumming, S. P., \& Katzmarzyk, P. T. (2018). Correlates of intensity-specific physical activity in children aged 9-11 years: a multilevel analysis of UK data from the International Study of Childhood Obesity, Lifestyle and the Environment. BMJ open, 8(2), e018373.

\section{Tables}


Table1. The table below shows the games, stages, levels, time, and records needed to obtain a badge

\begin{tabular}{|c|c|c|c|c|}
\hline level & games & time & point & badge number \\
\hline \multirow{3}{*}{1} & Ninja fruit & 5 minutes & Get 200 points & 1 \\
\hline & Super saver & 2 minutes & 65 ball catch & 1 \\
\hline & Traffic rider & 3 minutes & Get 28000 points & 1 \\
\hline & & & & \\
\hline \multirow{3}{*}{2} & Power beat & 5 minutes & Get 100000 points & 1 \\
\hline & Big brother & 2 minutes & Get 40000 points & 1 \\
\hline & Piano tiles & 3 minutes & Get 15 points & 1 \\
\hline & & & & \\
\hline \multirow{3}{*}{3} & Bear saber & 6 minutes & Get 2500 points & 1 \\
\hline & boxVR & 4 minutes & Passing normal phase & 1 \\
\hline & Raly taly & 5 minutes & 25 ball catch & 1 \\
\hline
\end{tabular}




\section{Table 2}

\begin{tabular}{lll}
\hline NO & questions \\
\hline 1 & I enjoy it \\
\hline 3 & I feel bored \\
\hline 4 & I dislike it \\
\hline 5 & I find it pleasurable \\
\hline 6 & It gives me energy \\
\hline 7 & It makes me sad \\
\hline 8 & It' very pleasant \\
\hline 9 & My body feels good \\
\hline 10 & I get something out of it \\
\hline 11 & It' very exciting \\
\hline 12 & It' frustrates \\
\hline 13 & It' not at all interesting \\
\hline 14 & It gives me a strong feeling of success \\
\hline 15 & It feels good \\
\hline 16 & I feel as though I would rather be doing something else \\
\hline
\end{tabular}




\begin{tabular}{|lllll|}
\hline \multicolumn{4}{|c|}{ Table 3. Results for males } & \\
\hline NO & Questions & $\mathrm{t}$ & $\mathrm{SD}$ & prob \\
\hline 1 & $\mathrm{Q} 1$ & 2.207 & 0.203 & 0.024 \\
\hline 2 & Q2 & -1.632 & 0.211 & 0.074 \\
\hline 3 & Q3 & 2.314 & 0.5 & 0.018 \\
\hline 4 & Q4 & 4.23 & 0.153 & 0 \\
\hline 5 & Q5 & -2.242 & 0.203 & 0.024 \\
\hline 6 & Q6 & -0.649 & 0.233 & 0.673 \\
\hline 7 & Q7 & -1.141 & 0.224 & 0.196 \\
\hline 8 & Q8 & 8.46 & 0.133 & 0 \\
\hline 9 & Q9 & 2.207 & 0.203 & 0.024 \\
\hline 10 & Q10 & 2.242 & 0.203 & 0.024 \\
\hline 11 & Q11 & 3.881 & 0.183 & 0.004 \\
\hline 12 & Q12 & -1.625 & 0.216 & 0.081 \\
\hline 13 & Q13 & -2.986 & 0.183 & 0.004 \\
\hline 14 & Q14 & 2.919 & 0.189 & 0.005 \\
\hline 15 & Q15 & 2.919 & 0.189 & 0.005 \\
\hline 16 & Q16 & -2.986 & 0.183 & 0.004 \\
\hline
\end{tabular}




\begin{tabular}{|lllll|}
\hline \multicolumn{4}{|c|}{ Table 4. Results for females } \\
\hline No & Questions & $\mathrm{t}$ & $\mathrm{SD}$ & prob \\
\hline 1 & Q1 & 2.316 & 0.173 & 0.028 \\
\hline 2 & Q2 & -3.347 & 0.159 & 0.002 \\
\hline 3 & Q3 & 2.366 & 0.169 & 0.025 \\
\hline 4 & Q4 & 7.099 & 0.113 & 0 \\
\hline 5 & Q5 & -3.347 & 0.159 & 0.002 \\
\hline 6 & Q6 & 0.357 & 0.187 & 0.725 \\
\hline 7 & Q7 & -1.468 & 0.182 & 0.153 \\
\hline 8 & Q8 & 7.099 & 0.113 & 0 \\
\hline 9 & Q9 & 3.347 & 0.159 & 0.002 \\
\hline 10 & Q10 & 2.316 & 0.173 & 0.028 \\
\hline 11 & Q11 & 4.752 & 0.14 & 0 \\
\hline 12 & Q12 & -0.367 & 0.182 & 0.716 \\
\hline 13 & Q13 & -7.483 & 0.107 & 0 \\
\hline 14 & Q14 & 6.205 & 0.118 & 0 \\
\hline 15 & Q15 & 4.752 & 0.14 & 0 \\
\hline 16 & Q16 & -3.969 & 0.151 & 0 \\
\hline
\end{tabular}

Figures 


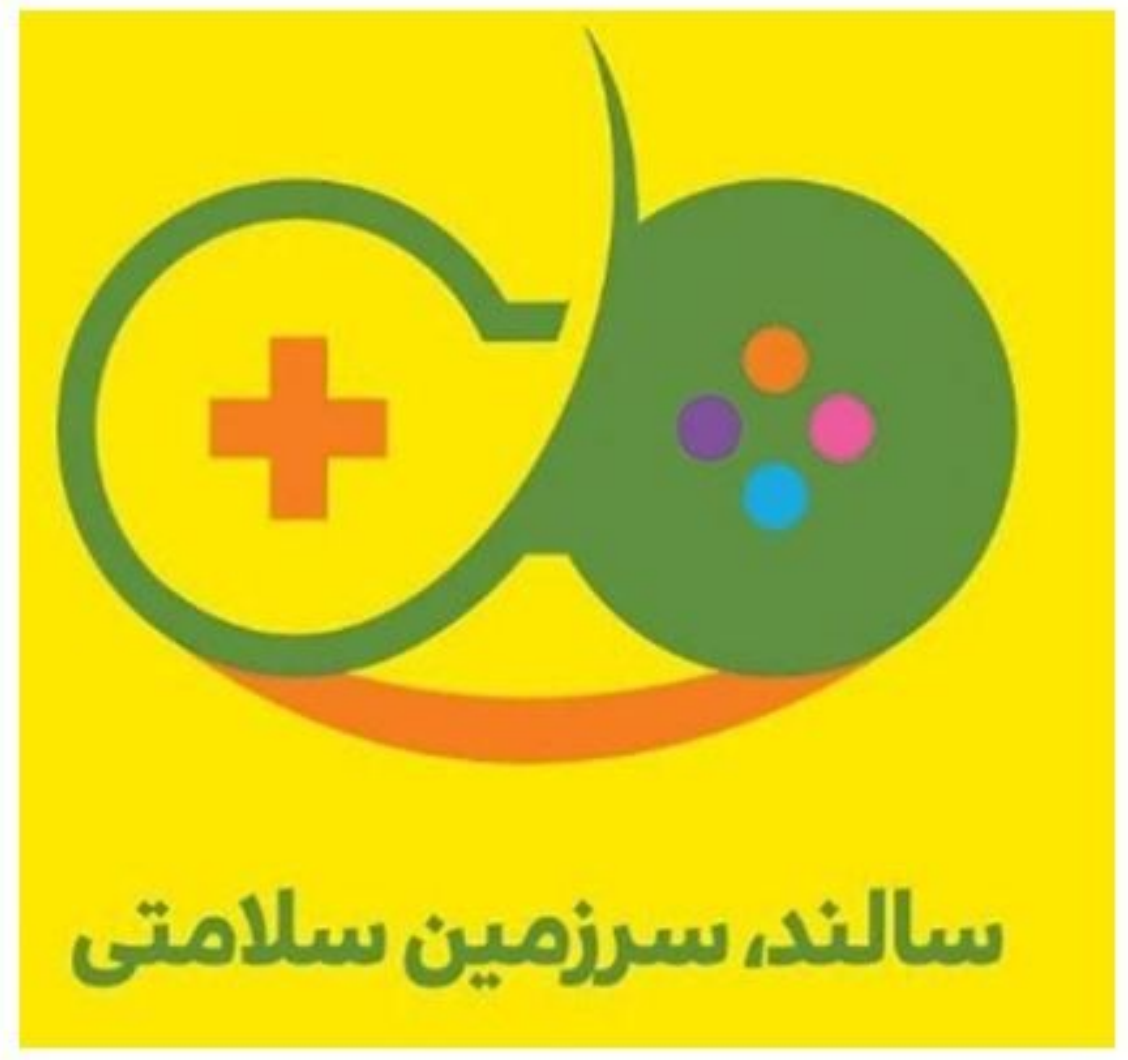

Figure 1

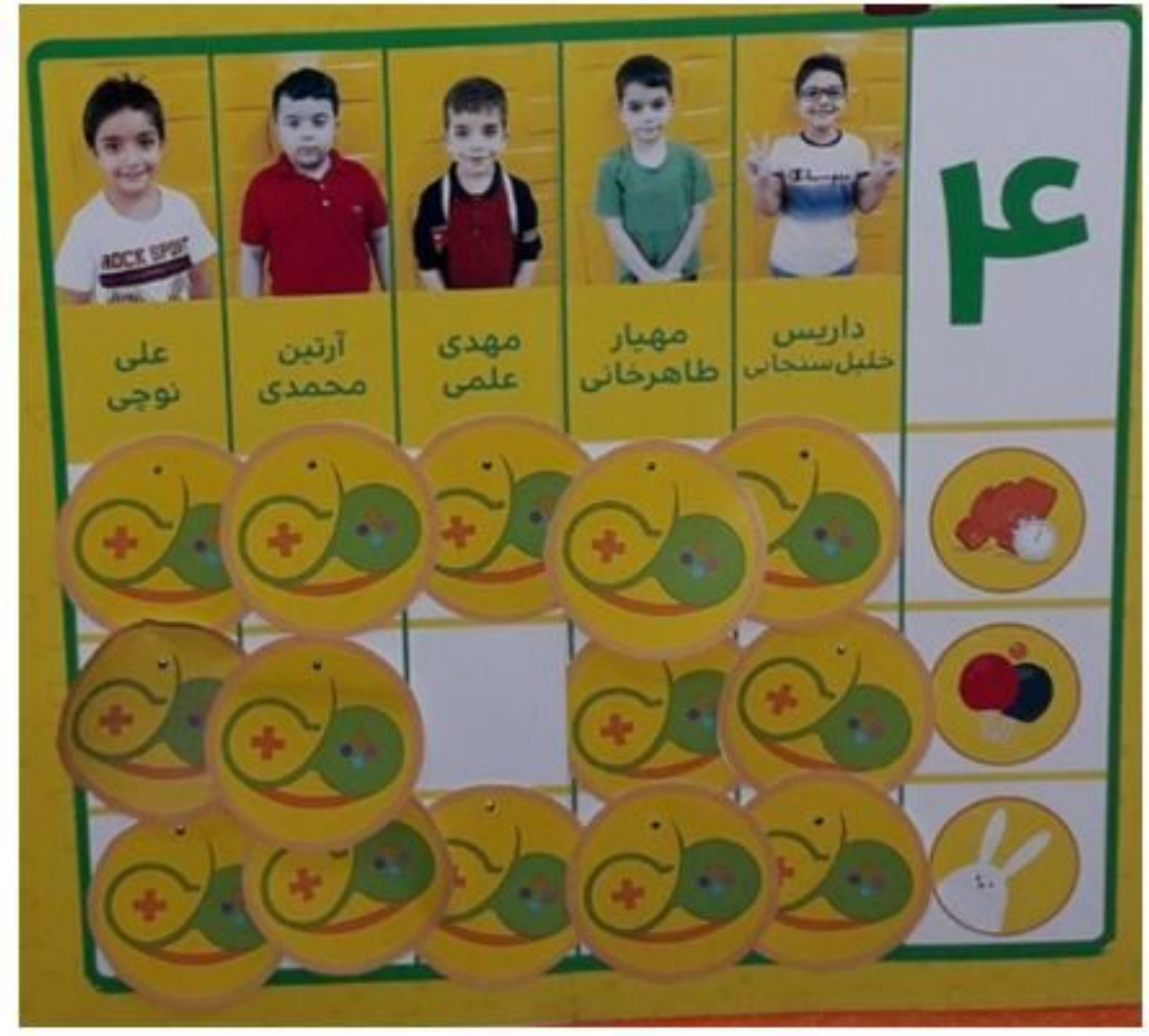

Figure 2 


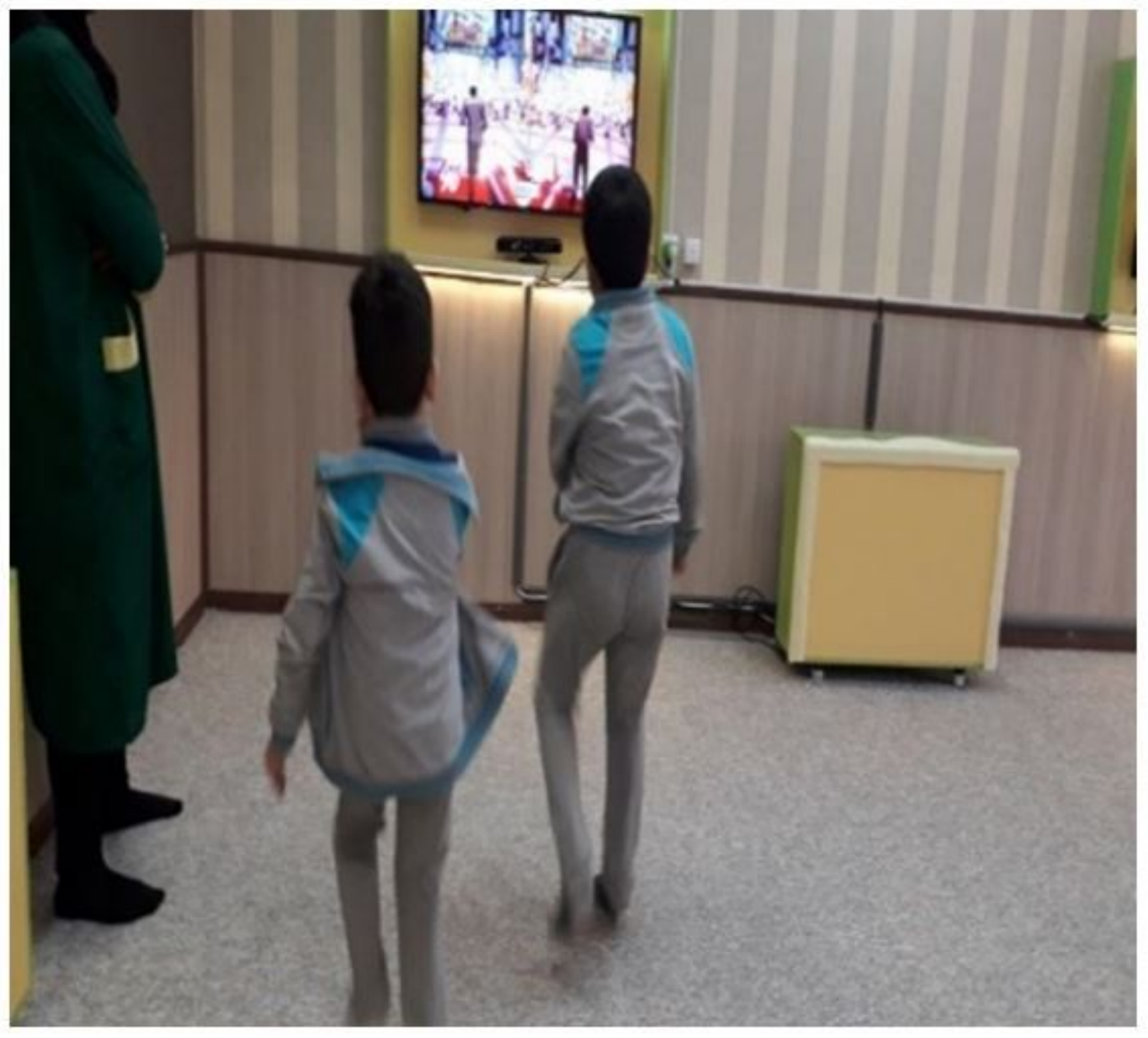

Figure 3 


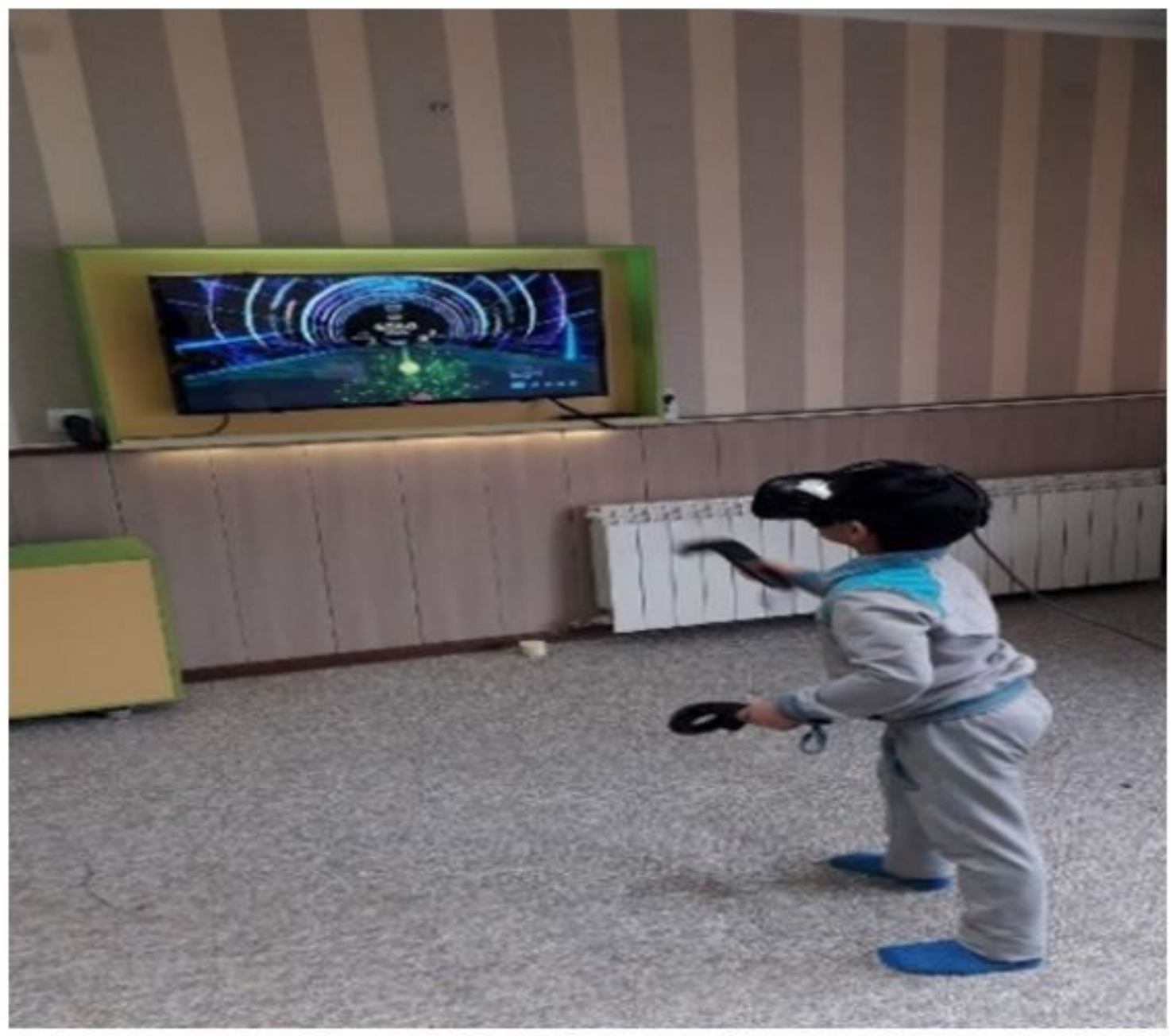

Figure 4 